\title{
VM Formula - A Formula for Estimating the Mesiodistal Width of Permanent Maxillary and Mandibular Canines in Adults
}

\author{
Meenakshni M. Tiwari ${ }^{1}$, Vikrant V. Jadhav², Ranjit Kamble ${ }^{3}$ Pallavi Daigavane ${ }^{4}$ \\ 1, 2, 3,4 Department of Orthodontics and Dentofacial Orthopaedics, Sharad Pawar Dental College and Hospital, \\ Sawangi, Wardha, Maharashtra, India.
}

\section{ABSTRACT}

\section{BACKGROUND}

Permanent canines are assumed to play an important role in achieving an ideal occlusion. So, determining accurate tooth size of canines becomes important for achieving acceptable aesthetics. Patients with missing canine lack perfect guidance during functional movements of mandible. Aim of this study was to determine a formula for missing permanent maxillary and mandibular canines.

\section{METHODS}

For the study, 300 models were analysed. The models were selected based on inclusion criteria, which included patients who had permanent teeth. They also had class I molar and canine relationships, average overjet and overbite and minimum amount of space discrepancy. For measuring the tooth dimensions accurately, digital vernier caliper was used. The data was analysed to arrive at the VM formula.

\section{RESULTS}

For maxillary canine, mean maxillary canine was minimum 0.58 and maximum 0.87 . Mean standard error was calculated for both the sides. It was 0.005 on right side and 0.004 on left side. Standard deviation (SD) calculated was 0.072 and average difference (error) was 0.05 with maxillary canine of right side and 0.04 error in maxillary canine of left side.

\section{CONCLUSIONS}

For achieving aesthetic profile, it is essential to calculate correct mesiodistal width of the teeth. Ideal tooth proportions play an important role in achieving good occlusion at the end of the orthodontic treatment.

\section{KEY WORDS}

Mandibular Canine, Maxillary Canine, Tonn's Ratio, Mesiodistal Width, Missing Incisor and Digital Caliper
Corresponding Author: Dr. Meenakshi Tiwari,

$J R$ 3, Department of Orthodontics and Dentofacial Orthopaedics, Sharad Pawar Dental College and Hospital, Sawangi, Wardha, Maharashtra, India.

E-mail: drmeenakshigaud@gmail.com

DOI: $10.14260 /$ jemds/2020/792

How to Cite This Article:

Tiwari MM, Jadhav VV, Kamble R, et al. VM formula - a formula for estimating the mesiodistal width of permanent maxillary and mandibular canines in adults. $J$ Evolution Med Dent Sci 2020;9(48):36013605, DOI: 10.14260/jemds/2020/792

Submission 13-05-2020,

Peer Review 13-10-2020,

Acceptance 20-10-2020,

Published 30-11-2020.

Copyright (c) 2020 Meenakshi M. Tiwari et al. This is an open access article distributed under Creative Commons Attribution License [Attribution 4.0 International (CC BY 4.0)] 


\section{BACKGROUND}

When any tooth has not erupted in the arch at its scheduled interval, orthodontist should formulate a detailed evaluation of the probable reasons accountable for missing and formulate the accurate treatment plan for treating the case. This tooth basically has potential to erupt in the oral cavity but is deferred in eruption. This is because its root formation is not completed. Other than this, impacted tooth is one that is unerupted in the oral cavity at the scheduled time interval, although its root formation is complete. It has lost its eruption potential leading to impaction of teeth. This knowledge has therapeutic application. This will guide us for the probable treatment plan in such cases. Reasons are to be formulated for its agenesis. Another concept is of over-retained teeth. This tooth may be extracted or in some cases may be preserved, depending on the conditions of roots and succedaneous tooth. In cases of over-retained teeth, maxillary canines ranks $3^{\text {rd }}$ with a frequency of $1 \%$. Determining whether to move a missing canine into its original place orthodontically or to substitute it prosthetically. ${ }^{1}$ This is most panic situation in Orthodontics. In case of an impacted canine, orthodontists should decide whether the available space has to be closed orthodontically. In such situation he takes help of radiographs. But, no such radiograph provides orthodontist with accurate mesiodistal width. This is because of lack of radiographic technology. So, orthodontist depends on model analysis for determining exact mesiodistal width of teeth. Till date no formula is available which determines width of missing canine in both maxillary and mandibular arch. There are many factors which plays an important role in deciding to remove the teeth or to reposition it orthodontically. These factors are age, sex and position of tooth. For this it is essential for the Orthodontist to decide the proper treatment plan for the impacted tooth. Every situation or condition of patient is different, so it essential to treat the condition accordingly. Mesiodistal width of missing teeth, should be determined separately in that situation. For this VM formula is developed. This study aim to provide a procedure for determining the mesiodistal dimension of permanent Maxillary and Mandibular Canine. It allows for determining the correct mesiodistal width with minimum errors.

Even though this condition is rare, but orthodontists should question themselves especially in cases of adult females, what they should remove an unerupted / impacted permanent canine rather than performing lengthy investigations and treatment protocols. During this condition, proper case history is very important. If patients provide history of previous history of extraction it would be helpful for practitioners to plan accordingly. For confirming this, dentist can take orthopantomograph (OPG). This will be helpful for further planning of case sequentially. If in case it is not extracted or is impacted then the condition becomes critical. Canine agenesis is fairly uncommon as compared to agenesis of 3rd molars. Maxillary permanent Canines is 8 th amongst the agenetic teeth. It has an incidence percentage for permanent maxillary and mandibular canines are $1.3 \%$ and $0.3 \%$ respectively. While studying the OPG carefully, orthodontists should make a clear judgement of absence or presence of canine. Sometimes, impacted canine is situated close to orbit. In such cases, this tooth is out of range of OPG. So, to avoid this, Orthodontist also has another radiograph on which he can study and diagnose the condition carefully. This is lateral cephalogram. Lateral cephalogram is part of routine orthodontic treatment. ${ }^{2}$

The tooth which has not erupted in the oral cavity at its planned time interval is known as over-retained tooth. Such type of tooth usually has potential to arrive in the oral cavity but is deferred for eruption, as the root is not completely formed. On the other hand, tooth which has not appeared in the oral cavity at the planned time interval though its root formation is completed, such tooth are impacted tooth. This type of tooth has lost its eruption potential. Over-retention is always follows impaction. The orthodontist should determine this difference between the teeth and plan accordingly. As seen earlier, over-retained tooth has the potential to erupt when the restriction or path is made clear for eruption. On the other hand, impacted tooth needs orthodontic traction to come into its desired position. Maxillary permanent canines are $3^{\text {rd }}$ in position showing frequency of $1 \%$, which is less as compared wisdom teeth. ${ }^{3}$

Orthodontist should do an accurate clinical analysis of impaction or over-retention for a maxillary and mandibular permanent canine by two methods i.e. inspection and palpation. This can used on both the surfaces i.e. buccal and lingual surfaces where the tooth is mostly placed. Recently, cone beam computed tomography is advanced way of diagnosing the impacted canine as it a three dimensional modality. But, study model will also provide valuable information of mesiodistal width of teeth. VM formula is developed for missing canines in both maxillary and mandibular arch. To properly achieve the aesthetic profile, correct dimension of tooth is needed. This is provided by VM formula. This is an innovative formula for determining the mesiodistal width of maxillary and mandibular canine.

When case is of missing / impacted / over-retained maxillary permanent canines, orthodontists has to prepare the case properly. At that time VM formula will help in determining will plan exact mesiodistal width of that teeth. ${ }^{2,3}$

\section{METHODS}

The observational study was approved by the institutional ethical committee (Ref No. DMIMS (DU) / IEC / 2018-19 / 7151). Patients who fulfilled the inclusion criteria were selected for the study. Informed consent was obtained from patients before stating the study. Sample size was taken as per the convenience of the study

\section{Inclusion Criteria}

- Patients having full permanent set of teeth.

- $\quad$ Patients with age group between 18 - 30 years of age.

- Patients which have molar and canine relation as Class I.

\section{Exclusion Criteria}

- Patients with missing, un-erupted and restored teeth.

- Patients with coronal coverage, attrition and deformed teeth. 
300 patients were selected for the study. For this, perfect impression of maxillary and mandibular arches were done. For this Putty impression material was used. After this, to avoid impression distortion, recorded impression were poured instantaneously. This was done with dental stone. After setting of dental stone, the cast were retrieved and trimmed accordingly. Bases were then made. Dimension in mesiodistal aspect were then recoded.

For deriving VM formula, permanent mandibular lateral incisor is used. Through different permutation and combination procedure, VM formula was derived.

\section{Statistical Analysis}

Statistical analysis was done to calculate mean, average difference, coefficient of variance and standard error

\section{RESULTS}

\section{VM Formula for Missing Maxillary Canine}

Mesiodistal width of both mandibular lateral incisors x 3 / 4 1.5

For permanent maxillary canine, firstly, mean was calculated. Mean was calculated with permanent maxillary canine and permanent mandibular lateral incisors was with lower value of 0.58 and higher value of 0.87 . After this, mean standard error (MSE) was derived for both the sides. This value was 0.004 and 0.005 on left side and right side respectively. Standard deviation (SD) of 0.072 is observed. Average difference (error) of 0.05 and 0.04 in right and left quadrant respectively. Co-efficient of variance (COV) was observed to be 0.03 for both the sides. Based on obtained results, correct VM formula was determined for our population. For VM formula, mesiodistal dimensions of permanent upper canine is determined by using mesiodistal dimensions of lower lateral incisors. Average Difference which was observed is same on both, right and left side of the arch The Average Difference was insignificant. For further accuracy of results \pm 0.5 is required

\section{VM Formula for Missing Mandibular Canine}

Mesiodistal width of both mandibular lateral incisors x 3 / 4 2.3

Firstly, mean was calculated. Mean was calculated with permanent maxillary canine and permanent mandibular lateral incisors was with lower value of 0.57 and higher value of 0.90. After this, mean standard error (MSE) was derived for both the sides. This value was 0.005 and 0.006 on left side and right side respectively. Standard deviation (SD) of 0.072 is observed. Average difference (error) of 0.04 and 0.03 in right and left quadrant respectively. Co-efficient of variance (COV) was observed to be 0.03 for both the sides. Based on obtained results, correct VM formula was determined for our population. For VM formula, mesiodistal dimensions of permanent upper canine is determined by using mesiodistal dimensions of lower lateral incisors. Average Difference which was observed is same on both, right and left side of the arch. The average difference was insignificant. For further accuracy of results \pm 0.5 is required

\section{VM Formula for Missing Maxillary Canine}

Mesiodistal width of both mandibular lateral incisors x $3 / 4-$ 1.5

\section{VM Formula for Missing Mandibular Canine}

Mesiodistal width of both mandibular lateral incisors x 3 / 4 2.3

For further accuracy of results \pm 0.5 is required.

\begin{tabular}{|cccccccccccccccc|}
\hline UR & 7 & 6 & 5 & 4 & 3 & 2 & 1 & 1 & 2 & 3 & 4 & 5 & 6 & 7 & UL \\
LR & 7 & 6 & 5 & 4 & 3 & 2 & 11 & - & 2 & 3 & 4 & 5 & 6 & 7 & LL \\
\hline \multicolumn{11}{c|}{ Table 1. Data Entry Table. (in mm) } \\
\hline
\end{tabular}

\begin{tabular}{|c|c|c|c|c|c|c|c|}
\hline \multirow[b]{2}{*}{ Authors } & \multirow{2}{*}{$\begin{array}{c}\text { Total } \\
\text { Patient } \\
\text { Number }\end{array}$} & \multicolumn{2}{|c|}{ Maxilla } & \multicolumn{2}{|c|}{ Mandible } & \multicolumn{2}{|c|}{ Total } \\
\hline & & $\begin{array}{l}\text { No. of } \\
\text { Cases }\end{array}$ & $\%$ & $\begin{array}{l}\text { No. of } \\
\text { Cases }\end{array}$ & $\%$ & $\begin{array}{l}\text { No. of } \\
\text { Cases }\end{array}$ & $\%$ \\
\hline $\begin{array}{c}\text { Stegemann } \\
\text { (1935) }\end{array}$ & 42,819 & 2 & 0.05 & 6 & 0.01 & 8 & 0.01 \\
\hline Dolder (1937) & 10,000 & 6 & 0.06 & 0 & 0 & 6 & 0.6 \\
\hline $\begin{array}{c}\text { Werther \& } \\
\text { Rothenberg } \\
\text { (1939) }\end{array}$ & 1000 & 4 & 0.4 & 2 & 0.2 & 6 & 0.6 \\
\hline Nagy (1953) & 3554 & 3 & 0.08 & 0 & 0 & 3 & 0.08 \\
\hline $\begin{array}{c}\text { Bredy \& } \\
\text { Hermann(1961) }\end{array}$ & 2316 & 13 & 0.56 & 7 & 0.3 & 20 & 0.86 \\
\hline Rose (1966) & 6000 & 6 & 0.1 & 1 & 0.02 & 7 & 0.12 \\
\hline Volk (1963) & 9533 & 2 & 0.22 & 1 & 0.05 & 3 & 0.03 \\
\hline $\begin{array}{l}\text { Bergstrom } \\
\text { (1977) }\end{array}$ & 2589 & 4 & 0.15 & 2 & 0.08 & 6 & 0.23 \\
\hline Davis (1987) & 1093 & 5 & 0.45 & 0 & 0 & 5 & 0.45 \\
\hline Holkari (2000) & 1524 & 6 & 0.2 & 1 & 0.07 & 4 & 0.26 \\
\hline Fukuta (2004) & 35,927 & 48 & 0.13 & 23 & 0.06 & 65 & 0.18 \\
\hline Fekonja (2005) & 212 & 1 & 2.1 & 0 & 0 & 1 & 2.1 \\
\hline $\begin{array}{l}\text { Altug-Atrac \& } \\
\text { Erdem (2007) }\end{array}$ & 3043 & 0 & 0 & 2 & 0.07 & 2 & 0.07 \\
\hline & $\begin{array}{r}\text { To } \\
\text { ermar }\end{array}$ & Co & 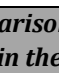 & $\mathrm{Da}$ & 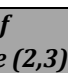 & & \\
\hline
\end{tabular}

\begin{tabular}{|cccc|}
\hline Clinical Findings & Male & Female & Total \\
Retained primary canine & 5 & 6 & 11 \\
Agenesis of other permanent teeth & 4 & 6 & 10 \\
Excluding the third molars & - & 1 & 1 \\
Supernumerary primary teeth & - & 1 & 1 \\
Supernumerary cups on permanent teeth & 4 & 5 & 9 \\
Malocclusions & Table 3. Dental Anomalies and Other Complications & \\
Accompanying Permanent Canine Agenesis & \\
\hline
\end{tabular}

\section{DISCUSSION}

Permanent canines are assumed to play an important role in achieving an ideal occlusion. Orthodontist often come across patients who have missing canines and these patients are therefore misplaced a key to perfect guidance during functional movements of mandible. The prevalence of missing teeth in the permanent dentition showed abundant disparities amongst populations with the prevalence rates between 3.9 and $11.3 \%$ in Caucasian population. Greater prevalence rates of $15.68 \%$ and $14.69 \%$ with no gender preferences in 
Hungarian population. According to Dahlberg's theory, oral cavity is divided into four fields, in which one of the field is canine field. Congenital canine agenesis is occasionally seen in oriental populations. Differences in the prevalence data is due to variation in statistics. Permanent maxillary and mandibular canine agenesis is 0.01 to $2.10 \%$. (Table 2 and 3).2,3

The developmental agenesis of canines is greater in female than males (1:2.2). The incidence of agenesis of both right and left mandibular permanent canine is rare. Lee et al in their study reported 6 cases of missing mandibular canine in Chinese population and Fukuta et al. reported similar 6 cases in Japanese population. In the data available, unilateral permanent maxillary canine agenesis is commonly seen than multiple or bilateral permanent canine agenesis. Fukuta et al. studied 37 such cases. (Maxillary - 26 and mandibular - 11) Agenesis of canines is usually seen in cases of over-retained deciduous teeth. Haselden et al. concluded that over-retained deciduous teeth show minimum root resorption, and these teeth need to be extracted. ${ }^{2,3}$ These conditions are well addressed in mixed deciduous dentition. But, problem arises when the condition occurs in permanent dentition. There are no such guidelines for assessing width of missing canine for both the dentition. To overcome these difficulties or complications, VM formula was determined. It included mesiodistal dimension of missing permanent maxillary or mandibular canine based on the combined i.e. both of right and left side dimensions of permanent mandibular lateral incisors.

There are different protocols or formulas to predict the width of missing teeth. Such a formula was developed by Tonn's. ${ }^{4}$ Tonn's designed a method to evaluate the dimension of absent maxillary lateral incisor. This method involved the mesiodistal dimension of incisors to measure the dimension of missing maxillary lateral incisor. Therefore, this formula was not possible to apply if any of the teeth are missing. Due to many calculations, this formula is tedious. Moreover, sample for Tonn's formula calculation was of Caucasian population. Therefore, when Tonn's formula was used in our population for determining width of missing teeth, imprecise values were observed. The formulas which are developed by TanakaJohnston ${ }^{5}$ and RN Staley, ${ }^{6}$ take the help of deciduous teeth for measuring the width of canines. These formulas are used in mixed dentition cases and not in permanent dentition cases. Tanaka-Johnston formulas applicability has been questioned by many researchers such as B Shrivastava ${ }^{7}$ and Sonahita ${ }^{8}$ for Indian population, but found variable results. This suggest ethnic variation and limitation of the formula. As, majority of cases reporting for orthodontic treatment are adult individuals, they do not have deciduous tooth left any more. Till date there is no such formula to benefit these individuals. Moreover, the formulas which are available to us during deciduous dentition stage are measured or formulated in Caucasian population. Many studies by Subbarao V et al, ${ }^{9}$ Saritha $\mathrm{T}$ et al, ${ }^{10}$ Patel et al ${ }^{11}$ etc. have documented the ethnic variation in mesiodistal dimension of teeth. So, it became important to determine the "VM formula". The VM formula is easy to use, understand and remember. This formula is advantageous to patients undergoing orthodontic treatment in case of missing Canine.

The occurrence of missing permanent maxillary canines is at average ratio. Therefore, missing canine is of great importance to orthodontist and general practitioner. As it is known that canines are cornerstone of the oral cavity. This is because of their position in oral cavity, as they are placed 3 teeth far from the centreline and moreover they separate the bicuspids from incisors. So, determining accurate tooth size of canines become important for achieving acceptable aesthetics. Almost, all the orthodontists find it difficult to determine the correct mesiodistal width of canine and in such cases fail to decide an accurate treatment plan. Till date mesiodistal width of canines was assessed on radiographs. But, magnification errors and radiation exposure have questioned the accuracy of the radiographic method. Relying on radiographic methods, orthodontist have failed to achieve correct results. So, there was a need to precisely plan a formula to evaluate mesiodistal width of canines in both the arch. Therefore, we came up with the VM formula which will solve the problem and improve accuracy regarding treatment planning on dental cast.

The VM formula was formulated by studying maxillary and mandibular cast of 300 patients. The mesiodistal dimension of the both (maxillary and mandibular) canines of right and left sides were calculated. This was done with the help of modified digital vernier calliper. This data was then systematically arranged in tabular format. After this mean and SD were measured. The calculated dimensions of the all the required teeth were then analysed. Further calculation were done on the theory of proportions. VM formula for scheming width of the missing maxillary canine was grounded on the collective width of permanent mandibular lateral incisors. The VM formula which was measured showed very negligible errors for our population. Which shows us that this formula is very well formulated to benefit individuals of our population. Error between measured and assessed standards of both right and left maxillary canine was $0.05 \mathrm{~mm}$ and $0.04 \mathrm{~mm}$ respectively. Similarly, error of $0.03 \mathrm{~mm}$ and $0.04 \mathrm{~mm}$ on right and left side respectively was observed for mandibular canine. The observed difference was in the $2^{\text {nd }}$ decimal place for canines of both arch. This error or difference designated the accurateness of the VM formula to calculate the outcomes. The formula that we propose is as follows -

\section{VM Formula for Missing Maxillary Canine}

Mesiodistal width of both mandibular lateral incisors x 3 / 4 1.5

\section{VM Formula for Missing Mandibular Canine}

Mesiodistal width of both mandibular lateral incisors x 3 / 4 2.3

Therefore, it was essential to develop a formula to determine the mesiodistal dimension of maxillary and mandibular canines of right and left side. As, mandibular lateral incisors are rarely missing, so they were selected in the formula. Moreover, these incisors seldom show any malformation. Due to digital calliper, measurement became easy and accurate. So, VM formula was derived to estimate the 
widths of missing maxillary and mandibular canines for our population. ${ }^{12-17}$

\section{CONCLUSIONS}

Impacted permanent maxillary and mandibular canines have incidence rates of $1.3 \%$ and $0.3 \%$ respectively. In the order of missing teeth, permanent maxillary canines are $8^{\text {th }}$. Missing maxillary canines have a psychosomatic consequence due to unaesthetic smile. Thus, in such patients it becomes very important to replace these teeth. In order to attain an adequate aesthetic and functional outcome, it is frequently essential to attain a harmonised, interdisciplinary method with orthodontist to recognize precise mesiodistal dimension of teeth. It is tough to determine the mesiodistal width of the missing canines when earlier dental records of the patient are not available. So, it is essential to visit a dentist at regular intervals.

Data sharing statement provided by the authors is available with the full text of this article at jemds.com.

Financial or other competing interests: None.

Disclosure forms provided by the authors are available with the full text of this article at jemds.com.

\section{REFERENCES}

[1] Zachrisson BU. Improving orthodontic results in cases with maxillary incisors missing. Am J Orthod 1978;73(3):274-89.

[2] Richardson G, Russell KA. Congenitally missing maxillary lateral incisors and orthodontic treatment considerations for the single-tooth implant. J Can Dent Assoc 2001;67(1):25-8.

[3] Tuverson DL. Orthodontic treatment using canines in place of missing maxillary lateral incisors. Am J Orthod 1970;58(2):109-27.

[4] Tonn P. Uber die mesio-distalen Zahn breiten relationen der Zahne des oberkiefers zudenents prechenden des unter kiefersbei normalen and anormalen occlusion. Diss. Berlin 1937

[5] Ling JYK, Wong RWK. Tanaka-Johnston mixed dentition analysis for southern Chinese in Hong Kong. Angle Orthod 2006;76(4):632-6.
[6] Staley RN, Kerber PE. A revision of the Hixon and Oldfather mixed-dentition prediction method. Am J Orthod 1980;78(3):296-302.

[7] Srivastava B, Bhatia HP, Singh R, et al. Validation of Tanaka and Johnston's analysis in western UP Indian population. J Indian Soc Pedod Prev Dent 2013;31(1):3642.

[8] Sonahita A, Dharma RM, Dinesh MR, et al. Applicability of two methods of mixed dentition analysis in a contemporary Indian population sample. Eur J Paediat Dent 2012;13(1):29-34.

[9] Subbarao VV, Regalla RR, Santi V, et al. Interarch tooth size relationship of Indian population: does Bolton's analysis apply? J Contemp Dent Pract 2014;15(1):103-7.

[10] Saritha T, Sunitha C, Kumar PK, et al. Applicability of bolton's analysis to a South Telangana population. Indian Journal of Dental Sciences 2017;9(4):225-32.

[11] Patel YV, Nair VS, Jamenis SC. Bolton analysis of the maratha population in Pune. J Dent Allied Sci 2017;6(1):811.

[12] Karia H, Shrivastav S, Karia AK. Three-dimensional evaluation of the airway spaces in patients with and without cleft lip and palate: a digital volume tomographic study. Am J Orthod Dentofacial Orthop 2017;152(3):37181.

[13] Thote AM, Sharma K, Uddanwadiker RV, et al. Optimum pure intrusion of a mandibular canine with the segmented arch in lingual orthodontics. Biomed Mater Eng 2017;28(3):247-56.

[14] Jadhav VV, Vasudevan SD, Kamble R, et al. ViVan formulaa modified formula for estimating the mesiodistal width of maxillary central and lateral incisor. J Evolution Med Dent Sci 2020;9(14):1144-7.

[15] Tiwari MM, Jadhav VV, Kamble RH, et al. A review on evolution and controversies regarding surgical methods and timing of palatoplasty in UCLP cases. J Evolution Med Dent Sci 2020;9(4):236-45.

[16] Tiwari MM, Daigavane PS, Kamble R, et al. Establishment of cephalometric norms for UCLP cases from central india population falling under goslon 1 and 2 based on burstone analysis. J Evolution Med Dent Sci 2020;9(16):1365-8.

[17] Ghoshal PK, Kamble RH, Shrivastav SS, et al. Radiographic evaluation of alveolar bone dimensions in the interradicular area between maxillary central incisors as safe zone for the placement of miniscrew implants in different growth patterns- a digital volume tomographical study. J Evolution Med Dent Sci 2019;8(51):3836-40. 